\title{
A Group Decision-Making Methodology with Incomplete Individual Beliefs Applied to e-Democracy
}

\author{
Alfonso Mateos • Antonio Jiménez-Martín • Sixto Ríos-Insua
}

\begin{abstract}
We consider the situation where there are several alternatives for investing a quantity of money to achieve a set of objectives. The choice of which alternative to apply depends on how citizens and political representatives perceive that such objectives should be achieved. All citizens with the right to vote can express their preferences in the decision-making process. These preferences may be incomplete. Political representatives represent the citizens who have not taken part in the decision-making process. The weight corresponding to political representatives depends on the number of citizens that have intervened in the decision-making process. The methodology we propose needs the participants to specify for each alternative how they rate the different attributes and the relative importance of attributes. On the basis of this information an expected utility interval is output for each alternative. To do this, an evidential reasoning approach is applied. This approach improves the insightfulness and rationality of the decision-making process using a belief decision matrix for problem modeling and the Dempster-Shafer theory of evidence for attribute aggregation. Finally, we propose using the distances of each expected utility interval from the maximum and the minimum utilities to rank the alternative set. The basic idea is that an alternative is ranked first if its distance to the maximum utility is the smallest, and its distance to the minimum utility is the greatest. If only one of these conditions is satisfied, a distance ratio is then used.
\end{abstract}

A. Mateos · A. Jiménez-Martín (四) · S. Ríos-Insua

Department of Artificial Intelligence, Technical University of Madrid, Campus de Montegancedo S/N, Boadilla del Monte, 28660 Madrid, Spain e-mail: ajimenez@fi.upm.es

\author{
A. Mateos \\ e-mail: amateos@fi.upm.es \\ S. Ríos-Insua \\ e-mail: srios@fi.upm.es
}




\section{Introduction}

The growth and development of information and communication technologies (ICT) has led to their widespread application, thus increasing their economic and social impact. The Organization for Economic Co-operation and Development (OECD) undertakes a wide range of activities aimed at improving our understanding of how ICT contribute to sustainable economic growth and social well-being and their role in the shift toward knowledge-based societies. Advances in ICT allow a much more substantive implementation of the democratic ideals. E-democracy articulates political and democratic procedures involving citizens in societal decision making through the use of ICT.

The debate on e-democracy has become very active recently. Although the initial common ideal democracy was the so-called plebiscitary model, in which citizens actively participate in public decision making through electronic voting, a more recent argument on e-democracy emphasized deliberation through ICT. For example, Barber (2000) argued that e-democracy should focus on citizens' participation in discussion and deliberation on public matters rather than on electronic voting. This so-called deliberative e-democracy model embraces ICT as a tool for implementing the public sphere described in Habermas (1989), where it is defined as "a place where private entities may draw together as a public entity and engage in rational deliberation, ultimately reaching consensus on common affairs".

Kim (2008) takes a pragmatic approach. An e-democracy model does not have to focus only on either participatory decision making or deliberation, since they are complementary rather than conflicting. Modern decision theory and group support systems can facilitate participation in decision making, while enhancing collective deliberation. Focusing on the process of public decision-making with citizen participation, this paper seeks answers to some of the critical questions in e-democracy.

Governments are paying special attention to promoting citizen participation, especially at the local level [Viraptirin 2006]. This is apparent, for example, from the more frequent implementation of participatory budgets, which are an attempt to give citizens a say in deciding how part of a public budget is spent. This is a budget allocation approach based on citizen involvement. It diverges from the predominant representative model in which citizens elect representatives for a certain period, and have practically no other direct opportunity to influence council policies. For example, Spain's Local Finance Regulatory Law does not prevent residents from participating in drafting a municipal budget, but it does not regulate such participation either. As a consequence, participation is usually limited to the obligation to publish the budget for a two-week consultation period, during which citizens can submit amendments. If there are none, the proposed budget comes into force; otherwise, a new plenary session would be necessary to sort out the amendments.

Participatory budgets are transforming the idea of a representative democracy, where citizens' preferences are considered just at elections for moving closer to a 
participatory democracy, based on direct participation and discussion of issues. As Souza (2001), one of the pioneers of participatory budgets, mentions, this is a process of direct, voluntary and universal democracy, providing the population with the opportunity to discuss budgetary issues and public policies, and make relevant decisions.

Though there are mentions of previous experiences, the most famous participatory budget was for Porto Alegre, initiated in 1989 and consolidated in 1992. Since then, it has been applied annually quite successfully (Abers 1998; de Sousa Santos 1998; Baierle 2004; Latendresse 2004). It received the United Nations prize for the best urban governance practices. Participatory budgets are becoming increasingly popular in many other municipalities all around the world. For example, more than 240 municipalities undertook such experiences of participatory budgets in 2004, not only in South America, but also in Italy, France, Germany, Belgium and Spain (UN-HABITAT 2004). Numerous cities are also planning to implement such a budget. Estimates are that citizen participation will be allowed in the discussion of $10 \%$ of the budget by 2010 .

Although participatory budget experiences are all grounded on relatively simple principles, a comparison of their regulations shows up many alternatives, including differences in the percentage of directly allocated budget, the number of participants, the number of rounds, etc.

(Ríos and Ríos Insua 2008) view participatory budgets as group resource allocation problems in which citizens try to agree on a budget on the basis of multiple criteria, possibly subject to other constraints apart from the maximum budget limit. They propose a framework for solving the participatory budget problem based on decision and negotiation analysis principles.

In this paper we introduce a group decision-making methodology that allows for incomplete individual beliefs, which will be illustrated by its application to edemocracy. We will consider $M$ alternatives (e.g. budgets) to be evaluated in terms of $L$ attributes (objectives). The aim is ranking the alternatives on the basis of the citizens' and political representatives' preferences for $L$ attributes. Because as many as possible of varying cultural levels should be involved, interaction with citizens should be carried out using user-friendly ICT to assure that all the citizens are able to express their beliefs and preferences.

The methodology can be used to represent and aggregate citizens' beliefs and preferences, and to rank the different alternatives on the basis of their expected utility. The paper consists of three more sections. Section 2 introduces the methodology. This section is divided into further sections explaining the aggregation of beliefs and the ranking of alternatives on the basis of expected utilities, respectively. In Sect. 3 an example of the methodology application is illustrated. Finally, Sect. 4 outlines the conclusions reached.

\section{Methodology}

The methodology we propose consists of the four phases shown in Fig. 1.

The first phase consists of defining the problem. Objectives must be identified. We recommend constructing an objective hierarchy, in which major objectives provide a basis for defining lower level objectives, since they are a means for achieving the 


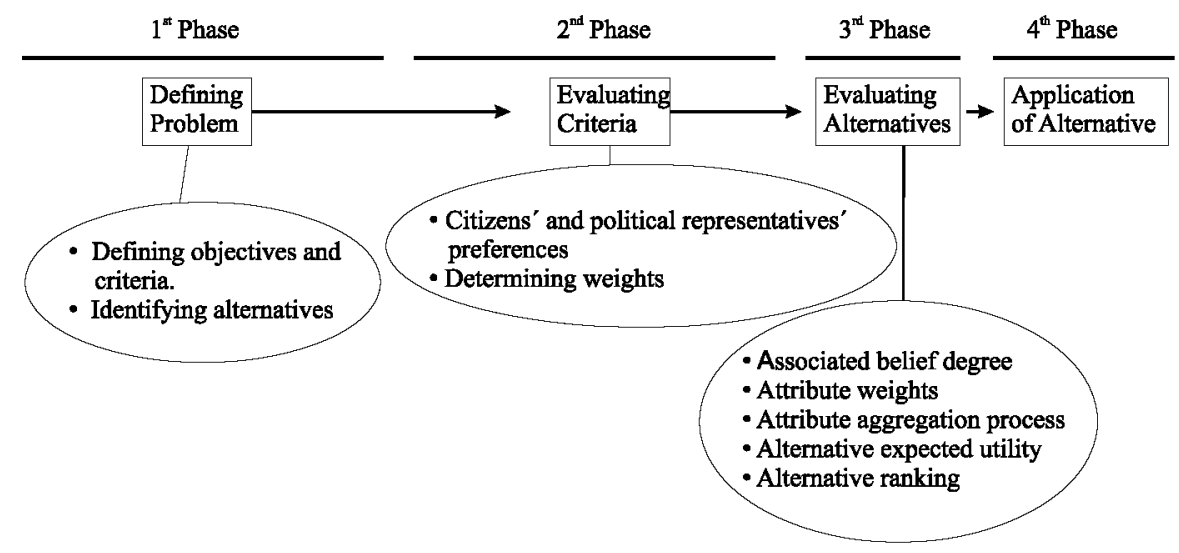

Fig. 1 Methodology phases

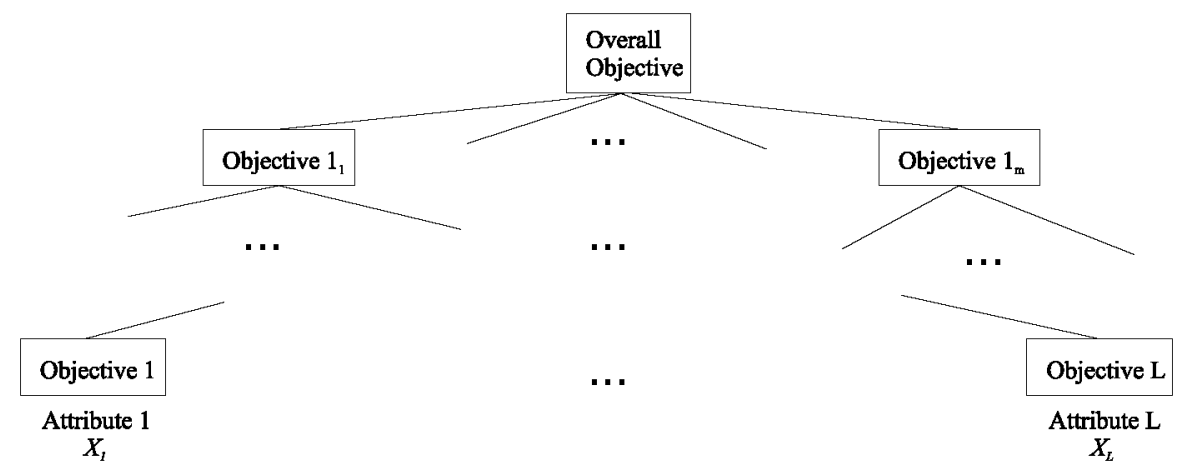

Fig. 2 Objective hierarchy

higher level goals (Brownlow and Watson 1987). Lower level objectives are more specific. Therefore, it is easy to identify reasonable attributes for these lowest level objectives to indicate to what extent they are achieved. See Keeney and Raiffa (1993) for some basic properties related to the set of attributes. Next, the different alternatives that can be applied must be identified.

This phase should involve politicians and experts, while considering the opinion of some properly chosen groups of citizens. This should lead to a clear enough problem definition for the whole society, explicitly determining the possible alternatives to be considered and the attributes for measuring the different objective achievement. One role of citizens is to verify that the way in which they are going to present the problem to the other citizens is clear enough. This phase will be carried out by attending meetings and exploiting ITC.

The first phase ends when an objective hierarchy is built up, which can be represented in a generic way as in Fig. 2, and attribute performances for each alternative $A^{i}$ are measured, i.e., the following matrix is available 


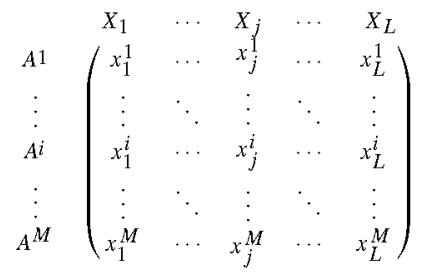

where $x_{j}^{i}$ is the performance for the alternative $A^{i}$ in attribute $X_{j}$.

In the second phase, citizens' and political representatives' preferences must be assessed. First, each of them must value the attribute performances by assigning them an achievement level from a well-defined set according to his/her beliefs and preferences. Let $y_{j}^{k i}$ be the belief degree associated with $x_{j}^{i}$ for the $k$ th participant. The methodology we propose accounts for incomplete information. Thus, there is no problem if no belief degree is assigned for an attribute performance.

Next, the participants have to provide the relative importance for the attributes. They will weight the attributes, and the system will perform a normalization process. There are many weighting methods that use different questioning procedures to elicit weights, see Stewart (1992) and Weber and Borchering (1993) for a review. Most account for imprecise information, see e.g. Pöyhönen and Hämäläinen (2001), Jiménez et al. (2006b) and Mustajoki et al. (2005).

Note that all citizens with the right to vote and political representatives take part in this phase.

The second phase ends once citizens and political representatives have assigned belief degree for the attribute performances, i.e. a belief level matrix

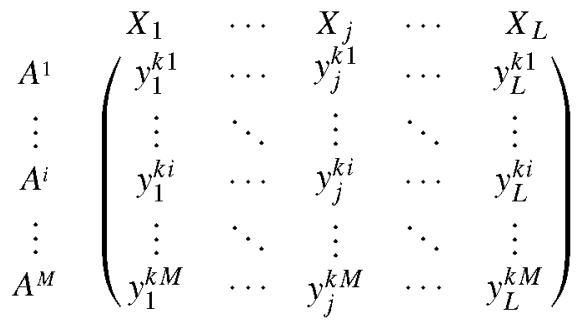

is available for each participant $k$ and, on the other hand, a weight vector representing the relative importance of the objectives is also available for each participant $k$

$$
w^{k}=\left(w_{1}^{k}, \ldots, w_{L}^{k}\right)
$$

where $w_{i}^{k}$ is the weight for the $i$ th attribute for participant $k$.

The third phase corresponds to the alternative evaluation phase. It involves the following stages:

1. First, a probability mass in the achievement level set can be identified for each attribute and alternative on the basis of the individual belief level matrices correspon-ding to each citizen and political representative. From now on we will denote it as the belief decision matrix. 
To assess it, as explained in more detail afterwards, we will compute the values for the citizens and political representatives, taking into account that political representatives represent the opinion of the citizens that do not take part in the budget decision-making process.

2. Weight elicitation Note that different weights have been provided by each participant for the attributes in the preference assessment. We finally consider as the attribute weight the weight interval whose lower end-point is 5th percentile and upper end-point the 95th percentile. Different percentiles could be used depending on the citizen percentage included in the weight interval. Note that we again consider that the weights elicited by political representatives represent the opinion of the citizens that do not take part in the process.

3. Attribute aggregation process At this point the belief decision matrix is available. The aim of this stage is then to aggregate all the attributes according to a methodology based on the Dempster-Shafer theory of evidence.

4. Alternative expected utility Since the weights for the attributes are assumed to be imprecise and represented by means of intervals, to assess alternative expected utilities it is necessary to solve two non-linear optimization problems, leading to the lower and upper utilities, respectively. Thus, $2 M$ optimization problems must be solved to obtain the expected utility intervals for all the alternatives under consideration.

5. Alternative Ranking This step consists of ranking the alternatives under consideration on the basis of their expected utility intervals. We propose using a distance notion that takes into account all the interval values. For this reason, we consider the distance as an integral. The most preferred alternative is the one that is furthest from the minimal and closest to the maximum utility. Since, this is not the case in most cases, we propose using a ratio that depends on the above to rank all the alternatives.

The fourth phase is the application of the most preferred alternative. This phase would be developed by the administration and would consist of the execution of the chosen alternative through the participatory decision-making process.

The steps that are being taken to execute the alternative should be constantly reported to citizens. If a large majority is unsatisfied with the selected alternative, an intermediate phase of negotiation could be carried out before the alternative execution, see e.g. Jiménez et al. (2005). However, if a very large number of citizens take part in the participatory decision making, the negotiation process could be very complex and a consensus solution is unlikely to be reached. For this reason we discard this option.

Next, we describe in more detail the third phase of the methodology (see Fig. 1), which corresponds with the automatic processing of all the information provided by the citizens and the political representatives.

\subsection{Belief Decision Matrix}

Let $d$ be the number of political representatives that represent $z$ citizens of a locality where a participatory process is going to be enacted. Both citizens and political rep- 
Table 1 Achievement level set

\begin{tabular}{l}
\hline Levels of achievement \\
\hline$H_{1}:$ Major negative impact \\
$H_{2}:$ Significant negative impact \\
$H_{3}:$ Moderately negative impact \\
$H_{4}:$ Negative impact \\
$H_{5}:$ Slightly negative impact \\
$H_{6}:$ No impact (status quo) \\
$H_{7}:$ Slightly positive impact \\
$H_{8}:$ Positive impact \\
$H_{9}:$ Moderately positive impact \\
$H_{10}:$ Significant positive impact \\
$H_{11}:$ Major positive impact \\
\hline
\end{tabular}

resentatives take part in the decision-making process. However, they have different weights, as explained afterwards.

Let us consider $M$ alternatives, $A^{1}, \ldots, A^{M}$, of which we want to select one on the basis of their performances for several attributes, denoted by $X_{1}, \ldots, X_{L}$. Participants have valued in the second phase the attribute performances by means an achievement level set $H=\left\{H_{1}, \ldots, H_{N}\right\}$ according to their beliefs and preferences. This has led to a belief level matrix for each participant $k$

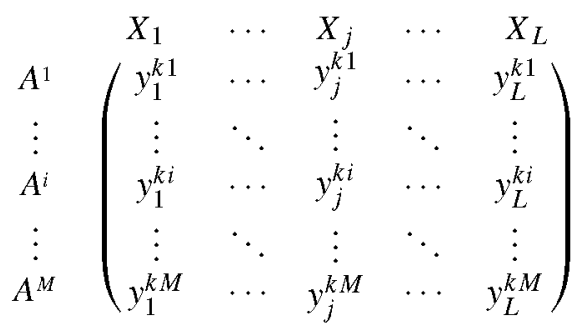

where $y_{j}^{k i} \in H$.

For example, the achievement level set $H$ used in Wang et al. (2006a), which analyses an environmental impact assessment problem, is shown in Table 1.

All the achievement levels are mutually exclusive and collectively exhaustive. Thus, they form what is termed a frame of discernment in Dempster-Shafer theory. Without loss of generality, it is assumed that level $H_{i+1}$ is preferred to level $H_{i}$.

Since $z$ is the number of citizens with the right to take part in the decision-making process (primarily, citizens with the right to vote and registered in the above locality) and $v$ is the number of citizens who really participate, then the number of citizens that do not take part in the process is $z-v$. We assume that the political representatives represent these $z-v$ citizens.

Thus, the weight of their vote is $(z-v) / z d$, while the weight for a citizen that really takes part in the budget decision-making process is $1 / z$.

If the alternative $A^{l}$ is assigned the level $H_{n}$ by $c_{i n}^{l}$ citizens and $d_{i n}^{l}$ political representatives for the attribute $X_{i}$, we consider that the belief degree in $H_{n}$ for the attribute 
$X_{i}$ in the alternative $A^{l}$ is $\beta_{n, i}\left(A^{l}\right)=c_{i n}^{l} / z+d_{i n}^{l}(\mathrm{z}-v) / z d$. Therefore, the assignment to alternative $A^{l}$ for the attribute $X_{i}$ is

$$
S\left(X_{i}\left(A^{l}\right)\right)=\left\{\left(H_{1}, \beta_{1, i}\left(A^{l}\right)\right), \ldots,\left(H_{N}, \beta_{N, i}\left(A^{l}\right)\right),\left(H, \beta_{H, i}\left(A^{l}\right)\right)\right\}
$$

where $\beta_{n, i}\left(A^{l}\right)$ is the belief degree associated with level $H_{n}$, and $\sum_{n=1}^{N} \beta_{n, i}\left(A^{l}\right) \leq 1$, and $1-\sum_{n=1}^{N} \beta_{n, i}\left(A^{l}\right)=\beta_{H, i}\left(A^{l}\right)$ repre-sents the unknown portion of achievement that could be assigned to any levels in the whole range denoted by $H$. Clearly, $\sum_{n=1}^{N} \beta_{n, i}\left(A^{l}\right)$ will be less than one when the citizens and political representatives taking part in the process do not assign a level to the attribute $X_{i}$ for the attribute $A^{l}$ since

$$
\begin{gathered}
\sum_{n=1}^{N} \beta_{n, i}\left(A^{l}\right)=\sum_{n=1}^{N} \frac{c_{i n}^{l}}{z}+\sum_{n=1}^{N} \frac{d_{i n}^{l}(z-v)}{z d}=1 \\
\sum_{n=1}^{N} c_{i n}^{l}=v \text { and } \sum_{n=1}^{N} d_{i n}^{l}=d .
\end{gathered}
$$

Note that $\beta_{H, i}\left(A^{l}\right)$ denotes total ignorance about the assess-ment of $A^{l}$ on $\mathrm{X}_{i}$.

The assignment results for each alternative $A^{l}$ and attribute $X_{i}$ are represented by the following belief decision matrix:

$$
\left.\begin{array}{cccccc} 
& X_{1} & \cdots & X_{j} & \cdots & X_{L} \\
A^{1} & S\left(X_{1}\left(A^{1}\right)\right) & \cdots & S\left(X_{j}\left(A^{1}\right)\right) & \cdots & S\left(X_{L}\left(A^{1}\right)\right) \\
\vdots & \vdots & \ddots & \vdots & \ddots & \vdots \\
A^{i} & S\left(X_{1}\left(A^{i}\right)\right) & \cdots & S\left(X_{j}\left(A^{i}\right)\right) & \cdots & S\left(X_{L}\left(A^{i}\right)\right) \\
\vdots & \vdots & \ddots & \vdots & \ddots & \vdots \\
A^{M} & S\left(X_{1}\left(A^{M}\right)\right) & \cdots & S\left(X_{j}\left(A^{M}\right)\right) & \cdots & S\left(X_{L}\left(A^{M}\right)\right)
\end{array}\right)
$$

\subsection{Determining Weights}

Each citizen (including the political representatives) can assign weight to the attributes according to their preferences, if necessary. The weights of the citizens are normalized, whereas we consider the weights for political representatives as $(z-v) / d$ citizens making this election. Afterwards, the 5th $\left(P_{5}\right)$ and the 95th $\left(P_{95}\right)$ percentiles for the weights assigned to each attribute $i$ are assessed, and $w_{i} \in\left[P_{5}, P_{95}\right]$ is considered as the weight for the $i$ th attribute. For simplicity we will denote this by $w_{i} \in\left[w_{i}^{-}, w_{i}^{+}\right]$.

\subsection{Aggregating Attributes}

Based on the belief decision matrix and the rule of evidence combination in DempsterShafer (D-S) theory, the analytical evidential reasoning (ER) algorithm is developed to aggregate $L$ attributes (Wang et al. 2007). The ER approach provides a non-linear attribute aggregation process. 
The ER algorithm first transforms the original belief degrees into basic probability masses by combining weights and belief degrees using the following equations:

$$
\begin{aligned}
e_{n, i} & =e_{i}\left(H_{n}\right)=w_{i} \beta_{n, i}\left(A^{l}\right), n=1, \ldots, N, i=1, \ldots, L, \\
e_{H, i} & =e_{i}(H)=1-\sum_{n=1}^{N} e_{n, i}=1-w_{i} \sum_{n=1}^{N} \beta_{n, i}\left(A^{l}\right), i=1, \ldots, L, \\
\bar{e}_{H, i} & =\bar{e}_{i}(H)=1-w_{i}, i=1, \ldots, L, \\
\tilde{e}_{H, j} & =\tilde{e}_{i}(H)=w_{i}\left(1-\sum_{n=1}^{N} \beta_{n, i}\left(A^{i}\right)\right), i=1, \ldots, L,
\end{aligned}
$$

with $e_{H, i}=\bar{e}_{H, i}+\tilde{e}_{H, i}$, where $w_{i}$ is the weight for the $i$ th attribute and $\sum_{i=1}^{L} w_{i}=1$, and $e_{n, i}$ represents the basic probability mass of $A^{l}$ being assessed as level $H_{n}$ for the attribute $X_{i}$. Note that the probability mass assigned to the whole set $H, e_{H, i}$ which is not currently assigned to any individual levels, is split into two parts; $\bar{e}_{H, i}$ and $\tilde{e}_{H, i}$, where $\bar{e}_{H, i}$ is caused by the relative importance of attribute $i$ and $\tilde{e}_{H, i}$ by the incompleteness of the assessment of the attribute $X_{i}$ for $A^{l} . \bar{e}_{H, i}$ represents what role the other factors can play in assessing the general factor (objective), and it is the proportion of beliefs that remain to be assigned depending upon how other factors are assesses. In essence, $\bar{e}_{I I, i}$ provides scope for conflict resolution in the presence of conflicting evidence. $\tilde{e}_{H, i}$ will be zero if nothing is missing in the assessment.

Next, the basic probability masses on the $L$ basic attributes are aggregated into the combined probability assignments using the following analytical formulae (Wang et al. 2006a, b, 2007):

$$
\begin{aligned}
& \left\{H_{n}\right\}: e_{n}=k\left[\prod_{i=1}^{L}\left(e_{n, i}+\bar{e}_{H, i}+\tilde{e}_{H, i}\right)-\prod_{i=1}^{L}\left(\bar{e}_{H, i}+\tilde{e}_{H, i}\right)\right] n=1, \ldots, N, \\
& \{H\}: \tilde{e}_{H}=k\left[\prod_{i=1}^{L}\left(\bar{e}_{H, i}+\tilde{e}_{H, i}\right)-\prod_{i=1}^{L}\left(\bar{e}_{H, i}\right)\right], \\
& \{H\}: \bar{e}_{H}=k\left[\prod_{i=1}^{L} \bar{e}_{H, i}\right],
\end{aligned}
$$

where

$$
k=\frac{1}{\sum_{n=1}^{N}\left(\prod_{i=1}^{L}\left(e_{n, i}+\bar{e}_{H, i}+\tilde{e}_{H, i}\right)\right)-(N-1) \prod_{i=1}^{L}\left(\bar{e}_{H, i}+\tilde{e}_{H, i}\right)} .
$$

The combined probability assignments are normalised into overall belief degrees by using the following equations: 


$$
\begin{aligned}
& \left\{H_{n}\right\}: \beta_{n}\left(A^{l}\right)=\frac{e_{n}}{1-\bar{e}_{H}}, \\
& \{H\}: \beta_{H}\left(A^{l}\right)=\frac{\tilde{e}_{H}}{1-\bar{e}_{H}},
\end{aligned}
$$

where $\beta_{n}\left(A^{l}\right)$ and $\beta_{H}\left(A^{l}\right)$ represent the overall belief degrees of the combined assessments, assigned to the assessment grades $H_{n}$ and $H$, respectively. Note that the last two equations provide a normalisation process for proportionally assigning the remaining belief $\bar{e}_{H}$ back to the focal elements after the combination of all basic factors. This step is necessary as $\bar{e}_{H}$ is not a degree of ignorance but the unassigned belief caused by the relative importance of the attributes.

The combined assessment is also a distribution assessment, which can be denoted by $S\left(y\left(A^{l}\right)\right)=\left\{\left(H_{1}, \beta_{1}\left(A^{l}\right)\right), \ldots,\left(H_{N}, \beta_{N}\left(A^{l}\right)\right),\left(H, \beta_{H}\left(A^{l}\right)\right)\right\}$. It provides a panoramic view of the alternative assessment, from which one can tell which levels the alternative $A^{l}$ is assessed to and what belief degrees are assigned to all the defined levels.

$$
\begin{gathered}
A^{1} \equiv S\left(y\left(A^{1}\right)\right), \\
\vdots \\
A^{l} \equiv S\left(y\left(A^{l}\right)\right), \\
\vdots \\
A^{M} \equiv S\left(y\left(A^{M}\right)\right) .
\end{gathered}
$$

The above formulas together constitute a complete ER analytical algorithm. Compare with evidence combination rule in D-S theory, the ER algorithm has at least the following features (Wang et al. 2006b):

(1) Taking into account the relative importance of evidence.

(2) Modeling ignorance clearly by breaking down unassigned probability mass into two parts and treating them differently.

(3) Generating rational conclusions in the combination of the multiple pieces of conflict evidence (Murphy 2000). Another methodology that generates rational conclusions is the Lateo Approach (Campos et al. 2007; Neves et al. 2007).

The consequence of having interval weights is that overall assessment can no longer be certain. In the ER framework, this would lead to intervals of overall combined belief degrees. Therefore there is a need to generate the upper and lower bounds of such an interval for each combined belief degree.

$\operatorname{Min} / \operatorname{Max} \beta_{n}\left(A^{l}\right)$ and $\beta_{H}\left(A^{l}\right)$ for $n=1, \ldots, N$

s.t.

$$
\begin{aligned}
& w_{i}^{-} \leq w_{i} \leq w_{i}^{+}, i=1, \ldots, L \\
& \sum_{i=1}^{N} w_{i}=1
\end{aligned}
$$




$$
\begin{aligned}
& \beta_{n}\left(A^{l}\right)=\frac{e_{n}}{1-\bar{e}_{H}}, n=1, \ldots, N \\
& \beta_{H}\left(A^{l}\right)=\frac{\tilde{e}_{H}}{1-\bar{e}_{H}}, n=1, \ldots, N \\
& \sum_{i=1}^{N} \beta_{n}\left(A^{l}\right)+\beta_{H}\left(A^{l}\right)=1 \\
& e_{n}=k\left[\prod_{i=1}^{L}\left(e_{n, i}+\bar{e}_{H, i}+\tilde{e}_{H, i}\right)-\prod_{i=1}^{L}\left(\bar{e}_{H, i}+\tilde{e}_{H, i}\right)\right], n=1, \ldots, N \\
& \tilde{e}_{H}=k\left[\prod_{i=1}^{L}\left(\bar{e}_{H, i}+\tilde{e}_{H, i}\right)-\prod_{i=1}^{L}\left(\bar{e}_{H, i}\right)\right] \\
& \bar{e}_{H}=k\left[\prod_{i=1}^{L} \bar{e}_{H, i}\right] \\
& k=\frac{\sum_{n=1}^{N}\left(\prod_{i=1}^{L}\left(e_{n, i}+\bar{e}_{H, i}+\tilde{e}_{H, i}\right)\right)-(N-1) \prod_{i=1}^{L}\left(\bar{e}_{H, i}+\tilde{e}_{H, i}\right)}{\bar{e}_{H, i}=1-w_{i}, i=1, \ldots, L} \\
& \tilde{e}_{H, i}=w_{i}\left(1-\sum_{n=1}^{N} \beta_{n, i}\left(A^{l}\right)\right), i=1, \ldots, L \\
& e_{n, i}=w_{i} \beta_{n, i}\left(A^{l}\right), n=1, \ldots, N, i=1, \ldots, L \\
& k=\frac{\sum_{n=1}^{N}\left(\prod_{i=1}^{L}\left(e_{n, i}+\bar{e}_{H, i}+\tilde{e}_{H, i}\right)\right)-(N-1) \prod_{i=1}^{L}\left(\bar{e}_{H, i}+\tilde{e}_{H, i}\right)}{e_{n, i}}=w_{i} \beta_{n, i}\left(A^{l}\right), n=1, \ldots, N, i=1, \ldots, L \\
& N
\end{aligned}
$$

If $\beta_{n}^{-}\left(A^{l}\right)$ and $\beta_{n}^{+}\left(A^{l}\right)$ are the optimal solutions of the $n$th min and max problems for $\beta_{n}\left(A^{l}\right)$, and $\beta_{H}^{-}\left(A^{l}\right)$ and $\beta_{H}^{+}\left(A^{l}\right)$ are the optimal solutions of the min and max problems for $\beta_{H}\left(A^{l}\right)$ then we have $\beta_{n}\left(A^{l}\right) \in\left[\beta_{n}^{-}\left(A^{l}\right), \beta_{n}^{+}\left(A^{l}\right)\right]$ and $\beta_{H}\left(A^{l}\right) \in\left[\beta_{H}^{-}\left(A^{l}\right), \beta_{H}^{+}\left(A^{l}\right)\right]$. The combined assessment is an interval distribution assessment given by

$$
S\left(y\left(A^{l}\right)=\left\{\left(H_{n}, \beta_{n}\left(A^{l}\right)\right), n=1, \ldots, N ;\left(H, \beta_{H}\left(A^{l}\right)\right)\right\}\right.
$$

with

$$
\sum_{n=1}^{N} \beta_{n}\left(A^{l}\right)+\beta_{H}\left(A^{l}\right)=1 .
$$


Note that $\beta_{H}\left(A^{l}\right)$ is zero if $\tilde{e}_{H, i}=0$ for all $i=1, \ldots, L$. This means that the combined assessment for the general attribute is complete if and only if all the original assessments for the basic attributes are complete.

Our approach makes no assumptions about the aggregated functional form, that is non-linear in general, and it only requires utility independence among individual attributes (Keeney and Raiffa 1993). The ER approach does not result in rank reversal, a phenomenon that might occur in analytical hierarchy process (AHP). This is because the ER approach models each decision alternative independently.

Both the D-S/AHP (Beynon et al. 2000, 2001; Beynon 2002a, b, 2005a, b) and the ER approaches are developed on the basis of the D-S theory of evidence, but they are quite different in nature. The former is an extension of the traditional AHP, while the latter has little to do with AHP. So, they are different in many ways such as modeling mechanisms, algorithms and so on. Other group decision-making approaches based on AHP have been proposed. For example, [Escobar 2003] introduces the so-called Aggregation of Individual Preference Structures (AIPS). This procedure incorporates ideas similar to Borda count methods and transfers to the case of preference structures the principle of aggregation employed in the two approaches traditionally followed in AHP-group decision making (aggregation of individual judgments and aggregation of individual priorities). In (Gargallo et al. 2007) a Bayesian approach of AHP group decision making based on mixtures for group identification is proposed and applied to e-democracy.

However, the attribute aggregation process of the ER approach is more complicated than several other multiattribute decision analysis methods, as multiattribute utility theory (MAUT). This shortcoming is to a large extent overcome by generating a window-based intelligent decision system software package ( $\mathrm{Xu}$ and Yang 2003) to support the implementation of the ER approach.

\subsection{Alternative Expected Utility}

Minimum and maximum utilities are introduced to rank $M$ alternatives. Suppose the utility of an assessment level $H_{n}$ is $u\left(H_{n}\right)$, then the expected utility of the aggregated assessment $S\left(y\left(A^{l}\right)\right)$ is defined as follows:

$$
u\left(S\left(y\left(A^{l}\right)\right)=\sum_{n=1}^{N} \beta_{n}\left(A^{l}\right) u\left(H_{n}\right)\right.
$$

Out of convenience and simplicity, $u\left(S\left(y\left(A^{l}\right)\right)\right)$ is usually referred to as the expected utility of $A^{l}$ for short. If the aggregated distribution assessment is incomplete, then $\beta_{H}\left(A^{l}\right) \neq 0$, which may be assigned to any assessment level. When it is assigned to the most preferred assessment level $H_{N}, u\left(S\left(y\left(A^{l}\right)\right)\right)$ reaches its maximum, which is defined by

$$
u_{\max }\left(A^{l}\right)=\sum_{n=1}^{N-1} \beta_{n}\left(A^{l}\right) u\left(H_{n}\right)+\left(\beta_{N}\left(A^{l}\right)+\beta_{H}\left(A^{l}\right)\right) u\left(H_{N}\right), l=1, \ldots, M .
$$


If $\beta_{H}\left(A^{l}\right)$ is assigned to the least preferred assessment level $H_{1}$, then $u\left(S\left(y\left(A^{l}\right)\right)\right)$ reaches its minimum, defined by

$$
u_{\min }\left(A^{l}\right)=\left(\beta_{1}\left(A^{l}\right)+\beta_{H}\left(A^{l}\right)\right) u\left(H_{1}\right)+\sum_{n=2}^{N} \beta_{n}\left(A^{l}\right) u\left(H_{n}\right), l=1, \ldots, M .
$$

As weights are given as intervals, the above defined utility measures are no longer unique. In fact, they become intervals as well. In such cases, we are interested in finding the overall maximum and minimum utilities of each alternative rather than the upper and lower bounds of either $u_{\max }\left(A^{l}\right)$ or $u_{\min }\left(A^{l}\right)$. The overall minimum utility for an alternative $A^{l}$ can be determined by solving the following non-linear optimization problem for $l=1, \ldots, M$ :

$$
\begin{aligned}
& U_{\min }\left(A^{l}\right)=\min u_{\min }\left(A^{l}\right)=\left(\beta_{1}\left(A^{l}\right)+\beta_{H}\left(A^{l}\right)\right) u\left(H_{1}\right)+\sum_{n=2}^{N} \beta_{n}\left(A^{l}\right) u\left(H_{n}\right) \\
& \text { s.t. } \\
& \qquad w_{i}^{-} \leq w_{i} \leq w_{i}^{+}, i=1, \ldots, L \\
& \sum_{i=1}^{N} w_{i}=1 \\
& \beta_{n}\left(A^{l}\right)=\frac{e_{n}}{1-\bar{e}_{H}}, n=1, \ldots, N \\
& \beta_{H}\left(A^{l}\right)=\frac{\tilde{e}_{H}}{1-\bar{e}_{H}}, n=1, \ldots, N \\
& \sum_{i=1}^{N} \beta_{n}\left(A^{l}\right)+\beta_{H}\left(A^{l}\right)=1 \\
& e_{n}=k\left[\prod_{i=1}^{L}\left(e_{n, i}+\bar{e}_{H, i}+\tilde{e}_{H, i}\right)-\prod_{i=1}^{L}\left(\bar{e}_{H, i}+\tilde{e}_{H, i}\right)\right], n=1, \ldots, N \\
& \tilde{e}_{H}=k\left[\prod_{i=1}^{L}\left(\bar{e}_{H, i}+\tilde{e}_{H, i}\right)-\prod_{i=1}^{L}\left(\bar{e}_{H, i}\right)\right] \\
& \bar{e}_{H}=k\left[\prod_{i=1}^{L} \bar{e}_{H, i}\right] \\
& \bar{e}_{H, i}=1-\sum_{n=1}^{N} e_{n, i}=1-w_{i} \sum_{n=1}^{N} \beta_{n, i}\left(A^{l}\right), i=1, \ldots, L \\
& \tilde{e}_{H, i}=w_{i}\left(1-\sum_{i}, i=1, \ldots, L\right. \\
& n=1
\end{aligned}
$$


The overall maximum utility can be determined by solving the same non-linear optimization problem using the following objective function:

$$
U_{\max }\left(A^{l}\right)=\max u_{\max }\left(A^{l}\right)=\sum_{n=1}^{N-1} \beta_{n}\left(A^{l}\right) u\left(H_{n}\right)+\left(\beta_{N}\left(A^{l}\right)+\beta_{H}\left(A^{l}\right)\right) u\left(H_{n}\right) .
$$

Therefore, each budget is still determined by a utility interval, as

$$
\begin{gathered}
A_{1} \equiv\left[U_{\min }\left(A^{1}\right), U_{\max }\left(A^{1}\right)\right], \\
\vdots \\
A_{l} \equiv\left[U_{\min }\left(A^{l}\right), U_{\max }\left(A^{l}\right)\right], \\
\vdots \\
A_{M} \equiv\left[U_{\min }\left(A^{M}\right), U_{\max }\left(A^{M}\right)\right] .
\end{gathered}
$$

\subsection{Alternative Ranking}

The above information is not meaningful enough to definitively choose a budget. We propose a method (Mateos et al. 2007) based on comparing the distances of each interval $A^{l} \equiv\left[U_{\min }\left(A^{l}\right), U_{\max }\left(A^{l}\right)\right], l=1, \ldots, M$ to some predetermined targets; the maximum utility $\left(U^{+}=\max _{l}\left\{U_{\max }\left(A^{l}\right)\right\}\right)$ and the minimum utility $\left(U_{-}=\right.$ $\left.\min _{l}\left\{U_{\min }\left(A^{l}\right)\right\}\right)$.

The idea is that an alternative is ranked first if its distance to the maximum utility $\left(U^{+}\right)$is the smallest, and its distance to the minimum utility $\left(U_{-}\right)$is the greatest. If only one of these conditions is satisfied, a solution might be outranked by the others depending upon the context of the problem (for example, the attitude of the DM in a decision-making situation). Another solution is to define a ratio for each alternative $A^{l}, l=1, \ldots, M$, as follows

$$
R\left(A^{l}\right)=\frac{D\left(A^{l}, U_{-}\right)}{D_{U_{-}}}-\frac{D\left(A^{l}, U^{+}\right)}{D_{U^{+}}},
$$

where the distance measure from $A^{l} \equiv\left[U_{\min }\left(A^{l}\right), U_{\max }\left(A^{l}\right)\right]$ to $U,\left(U^{+}\right.$or $\left.U_{-}\right)$is

$$
\begin{aligned}
D\left(A_{l}, U\right) & =\sqrt{\int_{-1 / 2}^{1 / 2}\left[\left(\frac{U_{\min }\left(A^{l}\right)+U_{\max }\left(A^{l}\right)}{2}+x\left(U_{\max }\left(A^{l}\right)-U_{\min }\left(A^{l}\right)\right)\right)-U\right]^{2} d x} \\
& =\sqrt{\left(\frac{U_{\min }\left(A^{l}\right)+U_{\max }\left(A^{l}\right)}{2}-U\right)^{2}+\frac{1}{3}\left(\frac{U_{\max }\left(A^{l}\right)-U_{\min }\left(A^{l}\right)}{2}\right)^{2}}
\end{aligned}
$$

and $D_{U-}=\max _{l}\left\{D\left(A^{l}, U_{-}\right)\right\}$and $D_{U+}=\min _{l}\left\{D\left(A^{l}, U^{+}\right)\right\}$. 
Note that we can assume, without loss of generality, that $D_{U-}>0$ and $D_{U+}>0$, because, obviously, $D_{U-}>0$ and if $D_{U+}=0$ then

$$
0=D_{U^{+}}=\min _{l}\left\{D\left(A^{l}, U^{+}\right)\right\}=D\left(A^{k}, U^{+}\right) .
$$

Therefore, $U_{\max }\left(A^{k}\right)=U^{+}=\max _{l}\left\{U_{\max }\left(A^{l}\right)\right\}$ is a single value and this alternative $A^{k}$ is the best because it has the highest utility and the problem is solved.

The ratio $R\left(A^{l}\right)$ for each alternative $A^{l}, l=1, \ldots, M$, measures how close alternative $A^{l}$ is to the maximum utility $U^{+}$and how far away it is from the minimum utility $U_{-}$. Besides, $R\left(A^{l}\right) \leq 0, l=1, \ldots, M$, because

$$
\left.\begin{array}{l}
D_{U_{-}} \geq D\left(A^{l}, U_{-}\right) \\
D_{U^{+}} \leq D\left(A^{l}, U^{+}\right)
\end{array}\right\} \Rightarrow\left\{\begin{array}{c}
\frac{D\left(A^{l}, U_{-}\right)}{D_{U_{-}}} \leq 1 \\
-\frac{D\left(A^{l}, U^{+}\right)}{D_{U^{+}}} \leq-1
\end{array} .\right.
$$

Note that $R\left(A^{l}\right)=0$, if $D_{U-}=D\left(A^{l}, U_{-}\right)$and $D_{U+}=D\left(A^{l}, U^{+}\right)$, then $A^{l}$ is the best alternative, because it is both the closest to the maximum utility $U^{+}$and the farthest away from the minimum utility $U_{-}$. However, $R\left(A^{l}\right)<0$, if it does not satisfy both equations simultaneously. Besides, the smaller $R\left(A^{l}\right)$ is the farther $A^{l}$ is away from $U^{+}$and the closer it is to $U_{-}$. Therefore, the alternative ranking would be realized by $R\left(A^{l}\right)$ in decreasing order.

\section{An Example}

In this section we will present a hypothetical example that illustrates the methodology that we have introduced and its potential. We consider an electric power problem in Spain. Electricity is generated principally at hydroelectric, thermo-electric or nuclear plants. Alternative sources of generation are wind, solar power or biomass, among others.

As more countries become industrialized the energy consumption is higher. World energy consumption has multiplied by 25 since the last century. In Spain, for example, the electric power demand increased from 14,625 million kilowatts in 1960 to 196,421 million in 2000. To cover this increase in the demand for electric power, it becomes necessary to increase generation. Depending on source of generation in question the associated environmental, social and economic impact will be different. For example, the generation of electric power by burning fossil fuels (oil, gas and coal) is known to be extremely pollutant. One of the most serious threats to the world environment comes from this pollution: the rapid increase of greenhouse gas emissions, especially $\mathrm{CO}_{2}$, is considered by many scientists to be the main culprit for overheating the Earth. On the other hand, nuclear plants produce practically no carbon dioxide, dioxide of sulphur or oxide of nitrogen emissions. However, Spanish citizens, politicians and the mass media continue to react vigorously to any slight accident at a nuclear plant.

To take a decision of this sort, then, it is necessary, besides examining the possible alternatives, to think about and try to minimize the possible impact on society, without 


\begin{tabular}{l}
\hline Levels of achievement \\
\hline$H_{1}:$ Absolutely negative \\
$H_{2}:$ Very negative \\
$H_{3}:$ Fairly negatively \\
$H_{4}:$ Slightly negative \\
$H_{5}:$ Average \\
$H_{6}:$ Slightly positive \\
$H_{7}:$ Fairly positive \\
$H_{8}:$ Very positively \\
$H_{9}:$ Absolutely positive
\end{tabular}

blocking a good option because it is not very popular. The way to keep up this balance is by supporting participatory democracy in conjunction with representative democracy.

Next we summarize the application of different phases of the proposed methodology to the considered problem.

Problem Definition In Spain 33,868,470 citizens have the right to vote (see http:// www.ine.es). Spanish citizens are represented by 350 deputies in the lower house of parliament (Congress of Deputies). Spain has an energy deficit and wants to solve this problem by generating more and importing less electric power. The necessary electric power can be generated as follows: $A^{1} \equiv 100 \%$ nuclear power, $A^{2} \equiv 100 \%$ wind power, $A^{3} \equiv 100 \%$ thermal energy, $A^{4} \equiv 100 \%$ solar power and $A^{5} \equiv 40 \%$ solar, $40 \%$ wind and $20 \%$ nuclear power.

Let's suppose that the government wants to take the decision participatively according to three attribute that represent the economic $\left(X_{1},\right)$ social $\left(X_{2}\right)$ and environmental $\left(X_{3}\right)$ impact of each alternative. The five alternatives should be clearly explained to the citizenship with experts' reports, where the economic, social and environmental impacts of each alternative should be explicitly detailed.

The citizens must express their beliefs on the impact of each alternative on all the attributes, i.e., specify one of the impacts in Table 2 for each alternative and attribute or leave unanswered if they do not know.

Evaluating Criteria Let's suppose that 10,000 citizens have taken part in the participatory process. Therefore, the weight for each citizen is $1 / 33,868,470=2.9526 \times 10^{-8}$, whereas the weight for each political representative is $33,858,470 /(33,868,470 \times$ $350)=2.8563 \times 10^{-3}$.

Thus, the social impact of nuclear power plants was rated as very negative $\left(H_{2}\right)$ by 2,500 citizens, slightly negative $\left(H_{4}\right)$ by 1,200 , average $\left(H_{5}\right)$ by 2000 , slightly positive $\left(H_{6}\right)$ by 1,700 and fairly positive $\left(H_{7}\right)$ by 800 , and the other citizens, $10,000-8,200=$ 1,800 , did not know or did not want to rate the social impact of nuclear plants. Now, the results of political representatives are: $164,148,10,8,7,5$ and 8 think that the social impact of nuclear plants is $\mathrm{H}_{2}, \mathrm{H}_{3}, \mathrm{H}_{4}, \mathrm{H}_{5}, \mathrm{H}_{6}, \mathrm{H}_{7}$ and $\mathrm{H}_{8}$, respectively. Taken together, then we have that the social impact of nuclear plants is as shown in Table 3. 
Table 3 Social impact of nuclear plants

\begin{tabular}{ll}
\hline & Probability \\
\hline$H_{2}$ & $2,500 \times 1 / 33,868,470+164 \times 33,858,470 /(33,868,470 \times 350)=0.46851$ \\
$H_{3}$ & $148 \times 33,858,470 /(33,868,470 \times 350)=0.42273$ \\
$H_{4}$ & $1,200 \times 1 / 33,868,470+10 \times 33,858,470 /(33,868,470 \times 350)=2.8598 \times 10^{-2}$ \\
$H_{5}$ & $2,000 \times 1 / 33,868,470+8 \times 33,858,470 /(33,868,470 \times 350)=2.2909 \times 10^{-2}$ \\
$H_{6}$ & $1,700 \times 1 / 33,868,470+7 \times 33,858,470 /(33,868,470 \times 350)=2.0044 \times 10^{-2}$ \\
$H_{7}$ & $800 \times 1 / 33,868,470+5 \times 33,858,470 /(33,868,470 \times 350)=1.4305 \times 10^{-2}$ \\
$H_{8}$ & $8 \times 33,858,470 /(33,868,470 \times 350)=0.02285$ \\
$H$ & $1,800 \times 1 / 33,868,470=5.3147 \times 10^{-5}$ \\
\hline
\end{tabular}

Thus,

$$
\begin{aligned}
S\left(X_{2}\left(A^{1}\right)\right)= & \left\{\left(H_{2}, 0.468\right),\left(H_{3}, 0.423\right),\left(H_{4}, 0.028\right),\left(H_{5}, 0.023\right),\left(H_{6}, 0.02\right),\right. \\
& \left(H_{7}, 0.014\right),\left(H_{8}, 0.023\right),(H, 0.00005\} .
\end{aligned}
$$

If the assessment is repeated for each attribute $\left(X_{i}\right)$ and alternative $\left(A^{l}\right)$, we get the following belief decision matrix

$$
\left.\begin{array}{cccc} 
& X_{1} & X_{2} & X_{3} \\
A^{1} & \left(S\left(X_{1}\left(A^{1}\right)\right)\right. & S\left(X_{2}\left(A^{1}\right)\right) & S\left(X_{3}\left(A^{1}\right)\right) \\
A^{2} & S\left(X_{1}\left(A^{2}\right)\right) & S\left(X_{2}\left(A^{2}\right)\right) & S\left(X_{3}\left(A^{2}\right)\right) \\
A^{3} & S\left(X_{1}\left(A^{3}\right)\right) & S\left(X_{2}\left(A^{3}\right)\right) & S\left(X_{3}\left(A^{3}\right)\right) \\
A^{4} & S\left(X_{1}\left(A^{4}\right)\right) & S\left(X_{2}\left(A^{4}\right)\right) & S\left(X_{3}\left(A^{4}\right)\right) \\
A^{5} & S\left(X_{1}\left(A^{5}\right)\right) & S\left(X_{2}\left(A^{5}\right)\right) & S\left(X_{3}\left(A^{5}\right)\right)
\end{array}\right)
$$

Solving $10(2 \times 5)$ non-linear optimization problems we obtain for each alternative the expected utility intervals shown in Fig. 3, output by means of the GMAA decision support system (http://www.dia.fi.upm.es/ ajimenez/GMAA), see e.g. Jiménez et al. (2003), 2006a.

The lower, average and upper expected utility is shown in Fig. 3 for the five alternatives under consideration. The GMAA ranks the alternatives on the basis of the average expected utilities. Note that the upper end-point of the utility interval for "Thermal Energy" is lower than the lower end-point utility for "Solar Power" and for "Mixture". Thus, "Thermal Energy" is dominated by the other two, and can be discarded. The utility intervals for the remaining alternatives are much overlapped, and all of them are non-dominated.

In any case, we calculate the distances of the utility intervals to the maximum and minimum utility to find out how robust this ranking is, see Table 4.

Looking at the third column in the Table 4, we find that the values are decreasing, i.e. the first alternative is the furthest from the worst utility and the last one is the closest. In the fourth column, the opposite applies, $A^{5}$ is the closest alternative to the best utility, and $A^{2}$ is the furthest one. Since our aim is to identify the most preferred alternative, 
Table 4 Distances to the maximum and minimum utility

\begin{tabular}{lllll}
\hline Alternatives & $U_{\min }\left(A^{l}\right)$ & $U_{\max }\left(A^{l}\right)$ & $D\left(A^{l}, U_{-}\right)$ & $D\left(A^{l}, U_{+}\right)$ \\
\hline$A^{5}:$ Mixture & 0.7645 & 0.9843 & 0.2257 & 0.1269 \\
$A^{4}:$ Solar Power & 0.7234 & 0.9276 & 0.1778 & 0.1694 \\
$A^{1}:$ Nuclear & 0.6578 & 0.8942 & 0.1365 & 0.2192 \\
$A^{2}:$ Wind Power & 0.6866 & 0.7833 & 0.0820 & 0.2509 \\
\hline
\end{tabular}

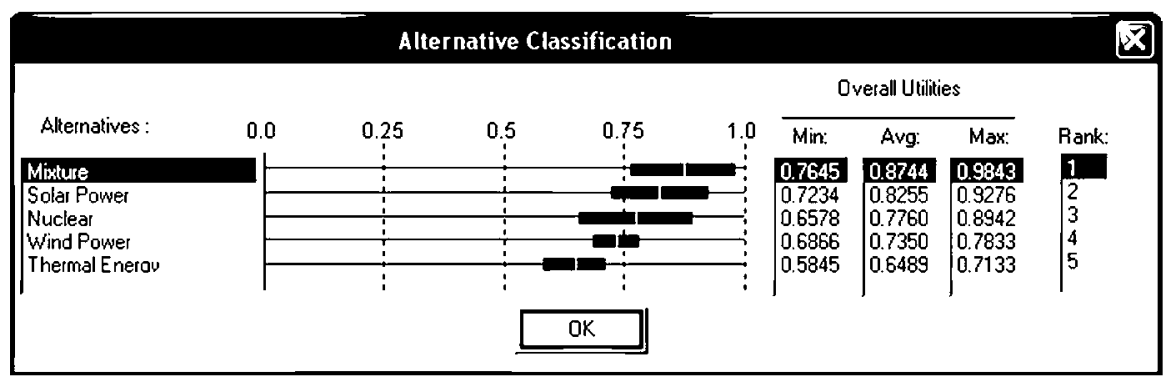

Fig. 3 Alternatives ranking in the GMAA system

i.e. the furthest from the worst utility and closest to the best one, we conclude that the most preferred alternative is generating extra electric power as follows: $40 \%$ solar, $40 \%$ wind and $20 \%$ nuclear power.

Additionally, as the distance ranking matches up with the one shown in Fig. 3, we can conclude that the ranking is robust, and the distance ratio does not need to be assessed.

\section{Conclusions}

Nowadays, representative democracy is in crisis, and scientists are proposing participatory democracy as a way out. In participatory democracy citizens do express not only their preferences in each election of political representatives but they can also take part in decision-making problems. There more pros than cons associated with this new way of looking at democracy.

Participatory budgets that are being implemented in a number of countries basically consist of allocating part of the locality's budget to items that the citizens agree to be the most important. These agreements are achieved by means of a negotiation process, which is normally enacted at regular meetings with the participation of political representatives. Through these meetings and on the basis of available information from new ICT, they build up a budget aimed at distributing the money that has been allocated. The different participatory budgets that are being implemented are very similar and differ depending on the locality only. It is true that a few are using scientific methods to reach a most preferred budget. 
In the literature we find algorithms aimed at calculating non-dominated budgets that account for citizens' preferences. In this paper we have tried to take the state of the art forward by assuming that several feasible alternatives exist and the problem is to select the one that best meets citizens' needs. If all the citizens take part in the decision-making process, the participation of political representatives would not be necessary. Nevertheless, this is a Utopian case since there are many circumstances preventing citizens from taking part. This is the reason why we believe that political representatives must represent those citizens that do not take part in the participatory process.

The methodology we propose assumes that there are different alternatives and one is selected on the basis of how well they perform for an objective set. It has the following phases:

1. Citizens and political representatives who take part in the participatory process express their preferences through some sort of ICT.

2. The system aggregates the preferences to get a probability mass of the performance of the alternatives for the identified attributes. It is assumed that the political representatives represent the percentage of citizens who have not taken part in the participatory process.

3. The system aggregates the attributes using a methodology based on the D-S theory of evidence. It calculates the probability mass of the possible values the overall objective can take when applying each alternative.

4. An expected utility is assessed for each alternative.

5. Alternatives, which are represented by utility intervals, are ranked on the basis of a distance notion that takes into account all the values of the utility interval.

Summarizing, we proposed an approach in which citizens and political representatives can express their preferences concerning different feasible alternatives to achieve specific attributes. Budgets were ranked depending on the citizens' preferences. Finally, an illustrative example was given.

This research opens up many other lines concerning participatory processes. Some of them follow. First, it can be almost directly extended to the situation in which each objective has its own assessment scale, even if some are quantitative and others are qualitative. On the other hand, the decision-makers' preferences could be imprecise. Additionally, a strict dominance notion has been considered, and more meaningful information could be output if a week dominance definition is assumed.

Acknowledgments The paper was supported by Madrid Regional Government project S-2009/ESP-1685 and the Spanish Ministry of Science and Innovation project MTM2011-28983-C03-03.

Prof. Sixto Ríos-Insua, co-author of this paper, recently passed away after a long illness. Sixto was a member of the Spanish Royal Doctoral Academy and co-founder and first president of the Spanish Group on MCDM. He co-authored more than 70 papers in international scientific journals, headed 14 national and international research projects, and received several prestigious awards. His teachings, inspiration and spirit will remain among us.

\section{References}

Abers R (1998) From clientelism to cooperation: local government, participatory policy, and civic organizing in Porto Alegre Brazil. Politics Soc 26:511-523 
Baierle S (2004) The case of Porto Alegre: the politic and background. In: Roussopoulos D, Benello CG (eds) Participatory democracy: prospects for democratizing democracy. Black Rose Books, Montreal, pp 175-236

Barber B (2000) Which technology for which democracy? Which democracy for which technology? Int J Commun Law Policy 6:1-8

de Sousa Santos B (1998) Participatory budgeting in Porto Alegre: towards a redistributive democracy. Politics Soc 26:461-510

Beynon M (2002a) DS/AHP method: a mathematical analysis, including an understanding of uncertainty. Eur J Oper Res 140(1):148-164

Beynon M (2002b) An investigation of the role of scale values in the DS/AHP method of MCDM. J Multi-Criteria Decis Anal 11:327-343

Beynon M (2005a) Understanding local ignorance and non-specificity within the DS/AHP method of multicriteria decision making. Eur J Oper Res 163(2):403-417

Beynon M (2005b) A method of aggregation in DS/AHP for group decision-making with the non-equivalent importance of individuals in the group. Comput Oper Res 32(7):1881-1896

Beynon M, Curry B, Morgan P (2000) The Dempster-Shafer theory of evidence: an alternative approach to multicriteria decision modelling. Omega 28:37-50

Beynon M, Cosker D, Marshall D (2001) An expert system for multi-criteria decision making using Dempster-Shafer theory. Expert Syst Appl 20:357-367

Brownlow SA, Watson SR (1987) Structuring multi-attribute value hierarchies. J Oper Res Soc 38:309-317

Campos F, Neves A, Campello de Souza FM (2007) Decision making under uncertainty. IEEE symposium on computational intelligence in multicriteria decision making, vol 1-5, pp 85-90

Gargallo P, Moreno-Jiménez JM, Salvador M (2007) AHP-group decision making: a Bayesian approach based on mixtures for group identification. Group Decis Negotiat 16:485-506

Habermas J (1989) Structural transformation of the public sphere. MIT Press, Cambridge

Jiménez A, Mateos A, Ríos-Insua S (2005) Monte Carlo simulation techniques in a decision support system for group decision-making. Group Decis Negotiat 14:109-130

Jiménez A, Ríos-Insua S, Mateos A (2003) A decision support system for multiattribute utility evaluation based on imprecise assignments. Decis Support Syst 36:65-79

Jiménez A, Ríos-Insua S, Mateos A (2006a) A generic multi-attribute analysis system. Comput Oper Res 33:1081-1101

Jiménez A, Ríos-Insua S, Mateos A (2006b) Using a combination of weighting methods in multiattribute decision-making. In: Haasis H-D, Kopfert H, Schönberger J (eds) Operations research proceedings 2005. Springer, Berlin, pp 767-772

Keeney RL, Raiffa H (1993) Decisions with multiple objectives. Wiley, New York

Kim J (2008) A model and case for supporting participatory public decision making in e-democracy. Group Decis Negotiat 17(3):179-193

Latendresse A (2004) The case of Porto Alegre: the participatory budget. In: Roussopoulos D, Benello CG (eds) Participatory democracy: prospects for democratizing democracy. Black Rose Books, Montreal, pp 287-291

Mateos A, Ríos-Insua S, Jiménez A (2007) Dominance, potential optimality and alternative ranking in imprecise multi-attribute models. J Oper Research Soc 58:326-336

Murphy CK (2000) Combining belief functions when evidence conflicts. Decis Support Syst 29:1-9

Mustajoki J, Hämäläinen RP, Salo A (2005) Decision support by interval SMART/SWING-incorporating imprecision in the SMART and SWING methods. Decis Sci 36(2):317-339

Neves AM, Campos FFC, Souza FMC (2007) The Lateo approach: a way to model the premises of the subjective uncertainty. Int J Inf Technol Intell Comput 2:85

Pöyhönen M, Hämäläinen RP (2001) On the convergence of multiattribute weighting methods. Eur J Oper Res 129(3):569-585

Ríos J, Ríos Insua D (2008) A framework for participatory budget elaboration support. J Oper Res Soc $59: 203-212$

Souza CU (2001) Participatory budgeting in Brazilian cities: limits and possibilities in building democratic institutions. Environ Urban 13:159-184

Stewart T (1992) A critical survey on the status of multiple criteria decision making theory and practice. OMEGA 20:569-586

UN-HABITAT (2004) 72 frequently asked questions about participatory budgeting, Urban Governance Toolkit Series 
Wang Y-M, Yang J-B, Xu D-L (2006a) Environmental impact assessment using the evidential reasoning approach. Eur J Oper Res 174:1885-1913

Wang Y-M, Yang J-B, Xu D-L, Chin K-S (2006b) The evidential reasoning approach for multiple attribute decision analysis using interval belief degree. Eur J Oper Res 175:35-66

Wang Y-M, Yang J-B, Xu D-L, Chin K-S (2007) On the combination and normalization of interval-valued belief structures. Inf Sci 177:1230-1247

Weber M, Borchering K (1993) Behavioral influences on weight judgements in multiattribute decision making. Eur J Oper Res 67:1-12

Xu DL, Yang JB (2003) Intelligent decision system for self-assessment. J Multi-Criteria Decis Anal 12:4360 